\title{
An Internet-Based Collaborative Engineering System
}

\author{
Hwagyoo Park \\ School of Management, Kyungdong University \\ San 91-1, Bongpo, Toseong, Goseong, Gangwon-Do, 219-832, Korea \\ hkpark@k1.ac.kr
}

\begin{abstract}
In the global competition of the 21st century manufacturing industry, collaborative engineering over the Internet is typically defined as the approach to integrating and exchanging manufacturing and design processes to shorten the product development cycle and reduce the cost as well as to provide a product that better meets the customer's expectations. The e-commerce technologies will have a profound impact on the practice and performance of the collaboration in engineering domain. In this paper, we propose an Internetbased collaborative engineering system in which decisions on product design, process design and manufacturing system design are simultaneously made at an initial phase of product development period over the Internet. The system is likely to help improve the engineering product development capability and quality over the Internet.
\end{abstract}

\section{Introduction}

As Internet-based collaborative engineering has become a major product development practice of the 21centry in the world class manufacturing, both small and large manufacturers are increasingly adopting the philosophy in designing and developing new products to shorten product development time while maintaining higher product quality, lower manufacturing costs, and satisfying customer's requirements ([2], [10]). Major obstacle to achieving this goal is the nature of distribution in collaboration [8]. There are three main distribution dimensions affecting collaborative work ([3], [4], [7], [10]). One is the geographical dimension, meaning that a project team consists of members from different localities. Another dimension is the disciplinary specialization. That is, team members usually come from diverse disciplines, each with particular expertise and contributing from their relevant areas. The third is the time dimension, implying that different team members participate in the project when available but not necessarily at the same time ([1], [6], [8]). These three issues must be effectively dealt with if the project is to succeed. With this motivation, we propose a framework of the Internet-based collaborative engineering system in which decisions on product design, process design and manufacturing system design are simultaneously made at an initial stage of product development period.

The product design agent develops a prototype of a knowledge-based design decision process using a feature-based solid modeling system. The feature-based product model [9] data are transferred to the process design agent to provide a generative process plan including manufacturing process selection, tool selection, 
technical parameter determination, and operation sequencing. The system design agent constructs an animated simulation model to establish performance measures, diagnose system performance, detect any bottleneck processes, and eventually propose the optimal system layout. Finally, the central control agent contains a control manager and a blackboard to provide primary controls of redesign processes and resolution of conflicts that may occur in the concurrent design decisions among three major agents.

As depicted in Fig. 1 above, the proposed system consists of four major agents. The system components and their functions are as follows.

- Product design agent to model a redesign process

- Process design agent to generate an automated process plan

- Manufacturing system design agent to provide an optimal manufacturing system layout

- Central control agent to control and coordinate the above three agents

The product design agent, process design agent and manufacturing system design agent individually contain domain knowledge bases and databases needed for solving their own problems, and the central control agent uses control knowledge sources to manage the concurrency and collaboration among three main agents.

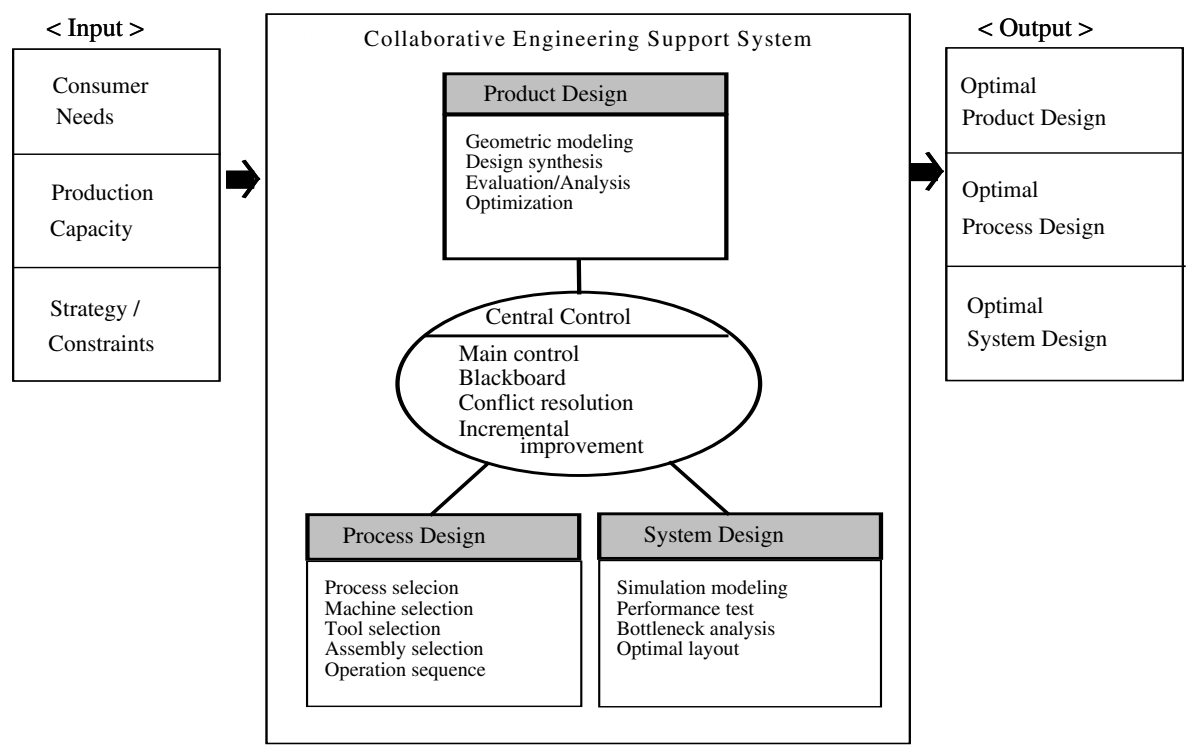

Fig. 1. Schematic Diagram of System Components

\section{Implementation Case}

The system was constructed as a Web server based on Internet Information Server (IIS) 4.0 for multi-users such as design, manufacturing or system administration expertise. These users can access the system through Web browsers that belong to the client. The Visual Basic script based on DCOM technology [5] was used primarily for implementation. The database was developed with Microsoft SQL Server 6.5. 
Implementation of the collaborative engineering system is described by the use of the real-life case for an escalator industry company in South Korea in this section. For the purpose of confidentiality, the company is referred as " $\mathrm{H}$ manufacturing company". Fig. 2 shows part design choice processes in the system.

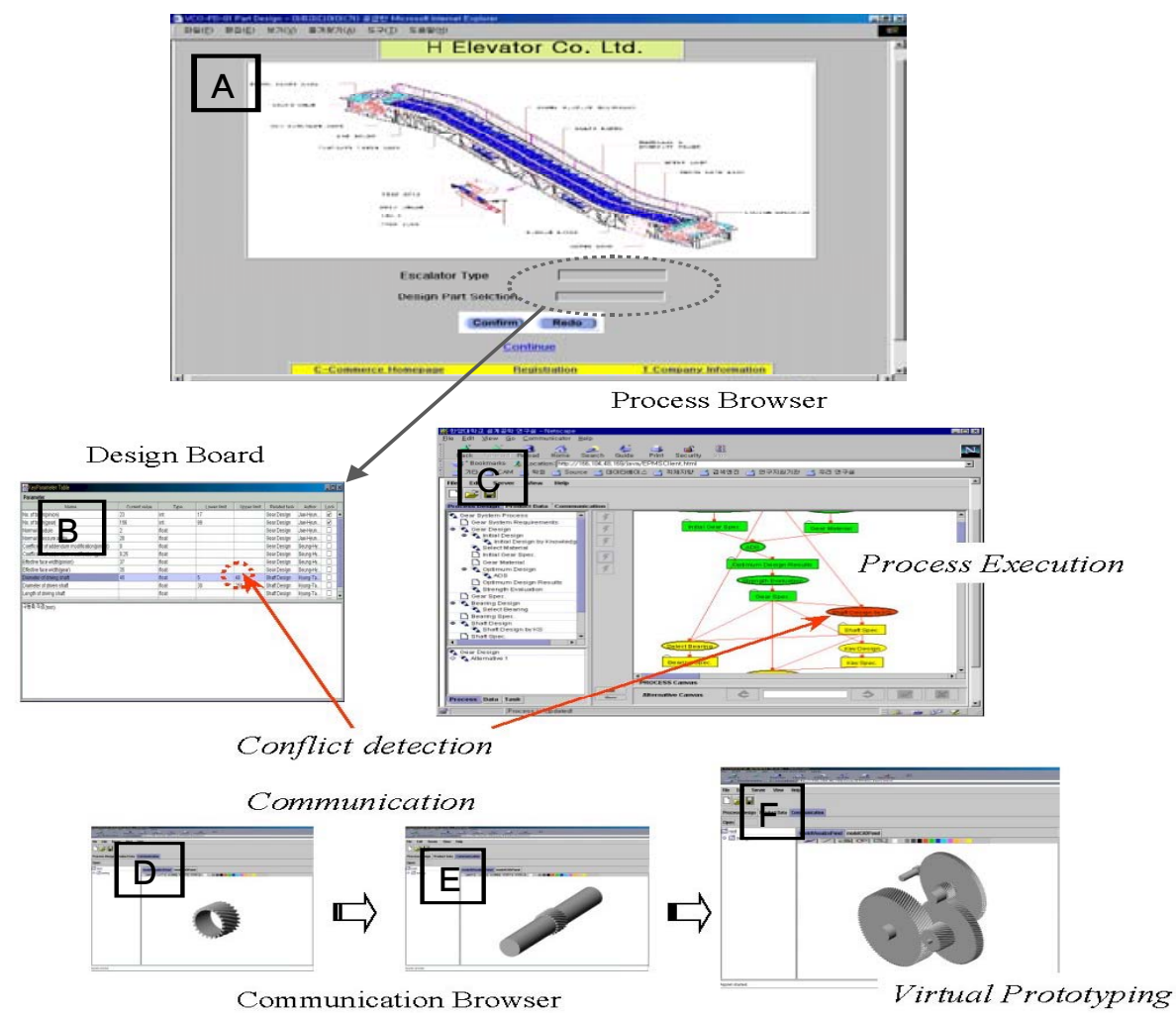

Fig. 2. System Implementation for "H Company"

"A" shows customer's part design specifications to generate design candidates by typing in escalator type and design part selection. The product design agent develops a prototype of a knowledge-based design decision process using a feature-based solid modeling system. The feature-based product model data are transferred to the process design agent to provide the design candidates as shown in "B". "E" shows final design output after checking conflict detection of "C" and "D" to see if selected part specifications are geometrically permitted for the required escalator type.

The representation of design geometry, including ideal geometry and geometric accuracy is generated. The parts relations between design descriptions and geometric descriptions are described as rules. "E" shows the most cost and time effective design for selected parts, gearbox example. It is found out using the optimization search scheme based on classification. Based on these, a virtual prototyping for the gear set is completed. Finally, the most cost and build effective design satisfies the design requirement and requires minimizing production cost, time, and manufacturability. 


\section{Conclusions}

The issue on improving collaborative engineering performance is closely associated with the search for innovative ways of conceptualizing cross-functional linkages that address the emerging contingencies of new product related task environments ([8], [10]). The Internet technology provides opportunities for the sharing of information among engineering product development team members, who may well be distributed in terms of both time and space ([1], [2]). The multimedia capability of the Web can be used to develop web-based applications that are equivalent to standalone systems in terms of functionality, performance and usability.

By adopting the collaborative engineering concept which can virtually bring together design and manufacturing teams along with key functions such as marketing, purchasing, human resources and corporate management, manufacturing companies are shortening product development lead time while improving product quality and cutting manufacturing costs. In this paper, we proposed a framework of a collaborative engineering system. The proposed system could be actually applied to a firm which designs and manufactures mechanical parts because it facilitates the integration of product and process design decisions collaboratively at a new product development phase.

\section{References}

[1] Afuah, A \& Tucci, C.L. (2000). Internet Business Models and Strategies: Text and Cases. McGraw-Hill.

[2] Barry, C. \& Lang, M. (2001). A survey of multimedia and web development techniques and methodology usage. IEEE Multimedia, 8(2), 52-60.

[3] Chen, Y.M. \& Liang, M.W. (2000). Design and implementation of a collaborative engineering information system for allied concurrent engineering. International Journal of Comput. Integrated Manufacturing, 16, 9-27.

[4] Cunliffe, D., (2000). Developing usable web sites: A review and model. Internet Research: Electronic Networking Applications and Policy, 10(4), 295-307.

[5] Eddon, G. \& Eddon, H. (1998). Inside Distributed COM, Micresoft Press.

[6] Ginige, A. \& Murugesan, S. (2001). Web engineering: an introduction. IEEE Multimedia, $8(1), 14-18$.

[7] O'Brien, A., (1998). An intelligent component model for building design, Second European Conference on Product and Process Modelling in the Building Industry, 19th21st, Oct.

[8] Rosenman, M.A. \& Wang, F.J. (1999). CADOM: a Component Agent Model based Design-Oriented Model for Collaborative Design, Research in Engineering Design II, 193-205.

[9] Shah, J. J. (1991). Assessment of Features Technology. Computer-Aided Design, . 23 (5), 331-343.

[10] Seybold, P.B. (2001). Get inside the lives of your customers. Harvard Business Review, May, 81-88. 